Leandro José Sousa Lima

Sobre a Situação do Livro Didático no Ensino das Artes Visuais

Brasília, 2011

Leandro José Sousa Lima 


\section{Sobre a Situação do Livro Didático nas Artes Visuais}

Trabalho de conclusão do curso de Artes Plásticas, habilitação em Licenciatura, do Departamento de Artes Visuais do Instituto de Artes da Universidade de Brasília.

Orientadora: Professora Vera Pugliese 


\section{Memorial}

Durante a passagem pela educação básica, tive a oportunidade de adquirir experiências dentro do campo das Artes Plásticas. Essa vivência, mesmo que limitada, acabou contribuindo muito para que meu interesse fosse direcionado, desde muito jovem, para esta área do conhecimento mais do que para qualquer outra. Naquele tempo, os alunos optavam entre artes cênicas ou visuais e, tal como ocorre hoje, o currículo de ensino valorizava mais o estudo de história da arte do que as práticas de ateliê.

No ano de 1997 , quando cursava a $6^{\circ}$ série, hoje correspondente ao $7^{\circ}$ ano, consegui aliar história e prática de arte por intermédio de uma oficina de desenho voltada para alunos que possuíam interesse nessa área do conhecimento e que trabalhava questões práticas como forma de ensino, desenvolvendo atividades paralelas às desenvolvidas na escola. Frequentei essa oficina até meu ingresso na Universidade de Brasília em 2003, no curso de Artes Plásticas e foi por intermédio dessa oficina que pude aliar história de arte com exercícios práticos.

Durante o curso, optei por uma dupla habilitação e, após a conclusão do curso de bacharelado em 2009, naturalmente acabei por chegar, no decorrer da licenciatura, às disciplinas de Estágios Supervisionados onde tive pela primeira vez oportunidade de acompanhar de perto o cotidiano de uma sala de aula. Nesta ocasião, pude detectar pessoalmente alguns problemas que até então só havia tomado ciência pelos meios de comunicação ou em conversas com colegas, como as deficiências de espaços físicos adequados destinados ao ensino de artes e o descaso de alguns alunos com relação à disciplina de Artes Visuais, a qual era considerada apenas uma disciplina de caráter meramente recreativo.

Assim, no decorrer dos estágios, diversas questões foram surgindo e, entre elas, uma especial com relação ao material didático. Chamou-me a atenção a falta de um material consistente que apoiasse o professor de artes em sala de aula. O conteúdo programático era transmitido no início do bimestre e cabia ao professor encontrar meios para trabalhá-lo em sala. Dessa forma, cheguei ao problema da pesquisa cujos resultados compuseram o presente TCC. 


\section{INTRODUÇÃO}

Atualmente, o estudo das Artes Visuais nas escolas públicas do Distrito Federal, em especial nas turmas de Ensino Fundamental, sofrem de uma grande defasagem no que diz respeito à complementaridade metodológica entre teoria e prática. Pensando em descobrir uma forma mais adequada de ensinar aos alunos de artes Plásticas na Educação Básica e fazer com que os mesmos compreendam os conteúdos de Artes em sua totalidade, surgiu um questionamento sobre como as Artes Visuais vem sendo trabalhadas na escola, mais precisamente se são embasadas no ensino de História da Arte ou concentram-se apenas em transmitir um repertório técnico para os alunos. Mais do que isso, se o professor oferece subsídios suficientes para o aluno desenvolver sua livre expressão artística.

Partindo-se do pressuposto de que algumas vezes as formas com as quais a Educação Artística ou Arte/Educação vem sendo trabalhada em sala de aula possa apresentar uma série de problemas ou equívocos, este projeto pretendia desenvolver uma proposta pedagógica em Artes Visuais que fosse capaz de proporcionar ao aluno de Ensino Fundamental uma educação estética em sua totalidade, isto é, aliando o ensino de história da arte e o fazer artístico. Nesse sentido, imaginei inicialmente que seria mais correto desenvolver algum tipo de material didático cuja metodologia aplicada orientaria um esquema de "projeto ou oficina de Artes Visuais". Este material deveria conter as diretrizes para orientar uma oficina de Artes Visuais que tivesse como finalidade principal trabalhar a teoria de arte de forma completa, levando em consideração que o processo de aprendizagem envolve vários aspectos. Essas diretrizes teriam prioritariamente o objetivo de integrar a teoria e a prática num único processo educativo, fazendo com que os alunos entendessem a importância do estudo de artes para que se chegasse à prática. Dessa forma, o estudante passaria a utilizar a carga teórica em atividades práticas, aprendendo a relacionar elementos da nossa visualidade.

No entanto, ao longo do desenvolvimento da pesquisa, percebeu-se que para chegar ao ponto de elaborar algum tipo de material seria necessário primeiramente que houvesse um diagnóstico da atual situação dos materiais didáticos que vem sendo utilizados em sala de aula. Esse diagnóstico acabaria por se constituir em um ponto de partida seguro cujos resultados poderiam futuramente subsidiar a elaboração de outros materiais didáticos, buscando-se assim colaborar para sanar as carências e oferecer um apoio mais consistente para o arte/educador em sala de aula.

Levando-se em consideração a carência de um diagnóstico a respeito da situação atual do material utilizado como apoio nas aulas de Artes Visuais, cogitou-se que seria mais interessante nesse momento desenvolver algo neste sentido. Assim, o projeto que segue se dispõe a esboçar um diagnóstico da situação em que se encontra o apoio didático das aulas de Artes Visuais. Mais 
precisamente, essa pesquisa objetiva identificar os pontos positivos e negativos de alguns desses materiais estimulando assim a reflexão e futuro aprimoramento destes mesmos materiais.

Nesse momento convém esclarecer que a elaboração de um diagnóstico a respeito dos materiais didáticos utilizados no campo do ensino das Artes Visuais trata-se em última instância, de um projeto que envolveria uma equipe multidisciplinar, com profissionais de áreas como estatística e abordando um universo de informações muito mais abrangente do que pretende-se apresentar aqui. Esse texto, por outro lado, apóia-se principalmente na vivência como professor estagiário na Secretaria de Educação do Distrito Federal e em conversas com outros profissionais das áreas das Artes Visuais que ocorreram no mesmo período além de entrevistas estruturadas por um roteiro.

Para tanto, foram selecionadas quatro escolas do Distrito Federal, sendo duas da Rede Privada de ensino e outras duas da Secretaria de Educação, distribuídas espacialmente pelo Distrito Federal. O critério de seleção utilizado para elaboração deste estudo preliminar de um possível diagnóstico foi basicamente a busca de amostras da diversidade geográfica do Ensino do Distrito Federal. É importante ressaltar que não se trata da problematização de um estudo de classes sociais mas deve-se levar em consideração a possibilidade de que algumas instituições de ensino possuírem melhores recursos do que outras. Assim, foram selecionadas uma escola particular do Plano Piloto, uma particular no Valparaíso e duas escolas públicas no Entorno, representando as classes economicamente desfavorecidas para realizar este estudo preliminar que visa contribuir para uma futura constituição de diagnóstico a respeito da atual situação dos materiais didáticos.

Sob esse aspecto, o desenvolvimento desta Monografia direciona sua atenção de forma especial para o material didático que está sendo utilizado por turmas do Ensino Fundamental da Secretaria de Educação do Distrito Federal entre $7^{\circ}$ e $8^{\circ}$ anos. Esta escolha se justifica por ser esta uma fase na qual percebi durante minha experiência em Estágio Supervisionado 1,2 e 3 que houve maior defasagem entre teoria e prática, além de outros pontos que pretendo explicitar no decorrer deste projeto.

Com isso, procura-se colocar em discussão uma série de questionamentos objetivando analisar e diagnosticar preliminarmente os materiais didáticos disponíveis para utilização por parte dos alunos, analisar se os professores possuem um material que lhes dê suporte para ministrar o conteúdo da melhor forma possível fazendo com que os educandos possam ter a oportunidade de aproveitar melhor o processo de ensino/aprendizagem.

Esta pesquisa se direciona principalmente para professores, estudantes universitários e estudantes da Educação Básica no sentido de que se possa conhecer e analisar o Ensino atual das Artes Visuais e estimular a reflexão e o aprimoramento de sua Metodologia de Ensino. 


\section{CAPÍTULO I}

\section{Um breve panorama do desenvolvimento do ensino de artes visuais}

Partindo da experiência adquirida nas disciplinas de Estágio Supervisionado 1, 2 e 3 além de um roteiro de entrevistas e conversas informais com professores e coordenadores ao longo do curso de licenciatura no período em que se desenvolveu o presente estudo, foi possível constatar que existe uma série de problemas que envolvem o ensino das Artes Visuais no Brasil. Entre eles podemos citar a falta de um local adequado para a prática da Educação Artística e, mais grave do que isso, há também a questão do preconceito com relação à Arte, que é considerada pela maioria dos alunos apenas um lazer entre as aulas de Física e Matemática (sic.), por exemplo.

É possível que isso se deva ao fato de que a área de que trata da educação escolar em Artes Visuais possua um percurso relativamente recente e coincida com as transformações educacionais que caracterizaram o século XX em várias partes do mundo. Assim, as diversas pesquisas que foram desenvolvidas nos mais variados campos das Ciências Humanas trouxeram informações muito importantes a respeito do desenvolvimento cognitivo da criança, sobre o processo criador e sobre a modalidade artística de outras culturas. Essas pesquisas, por sua vez, possibilitaram a diversos pensadores formular princípios inovadores para o ensino em artes visuais, música, teatro e dança. (PCN, vol. 6, pág. 20)

Pode-se afirmar que a principal contribuição desses novos princípios foi reconhecer "a arte da criança como uma manifestação espontânea e auto-expressiva" (Parâmetros Curriculares Nacionais: Arte/Secretaria de Educação, 1997, volume 6, pág. 20). Assim, esses princípios valorizavam a livre expressão e a sensibilidade como uma espécie de energia propulsora para experimentação artística, ou seja, suas propostas educacionais eram centradas na questão do desenvolvimento do aluno.

Nesse momento é importante chamar a atenção para o fato de que mesmo que tais princípios tenham trazido uma contribuição inegável no sentido de que passamos a valorizar a produção criadora das crianças, eles foram responsáveis pelo problema anteriormente citado, de que as Artes Visuais ficaram relegadas a uma disciplina de caráter meramente recreativo. O que ocorreu foi que a necessidade e a capacidade artística acabou por se enquadrar em lugares comuns como, por exemplo, o de que importava era na verdade o processo criador da criança e não o seu produto final, ou ainda o princípio "de aprender a fazer, fazendo" (PCN, vol. 6, pág. 20). Isso acabou por gerar a banalização do "simplesmente deixar fazer", permitindo assim ao aluno a liberdade para desenvolver sua arte sem nenhum tipo de intervenção por parte do docente. Dessa forma, o professor de artes passou a ter paulatinamente um papel cada vez mais passivo e por vezes até irrelevante. 
Esta situação praticamente se prolongou até o início da década de 1960 quando alguns arte/educadores passaram a questionar principalmente a idéia do desenvolvimento livre e espontâneo da expressão artística da criança e procuraram definir qual era a real contribuição da arte para a educação do ser humano. Isso desencadeou uma tendência que tinha como objetivo definir o fenômeno artístico como conteúdo curricular. Esse fato acabou por se articular em dois movimentos: de um lado a revisão crítica da livre expressão e de outro o estudo da natureza como forma de conhecimento. Levando-se em consideração que o pensamento destes arte/educadores estava atrelado ao momento histórico, a crítica à livre expressão passou a questionar a aprendizagem artística como conseqüência direta do processo de amadurecimento da criança. (PCN, 1997, pág. 21)

Essa situação acabou por modificar-se no inicio da década de 1970, quando alguns autores responsáveis pela mudança de rumo do ensino das artes nos Estados Unidos passaram a compreender o desenvolvimento artístico como um resultado de formas complexas de aprendizagem, não se desenvolvendo por si só à medida que o aluno amadurecia. Isso quer dizer que caberia ao professor promover essa aprendizagem por meio da instrução. (PCN, 1997, pág. 21)

A própria criação dos Parâmetros Curriculares Nacionais - PCN resultou dessa nova forma de pensamento que passou a compreender o ensino como fenômeno mais complexo. Pensando em responder à necessidade de referências a partir das quais o sistema educacional do país se organize, as autoridades governamentais tentaram garantir que fossem respeitadas as diversidades culturais, regionais, étnicas, religiosas e políticas que atravessam uma sociedade complexa como a nossa e que atuasse de forma definitiva no processo de construção da cidadania.

\section{O ensino de artes no Brasil}

O ensino das artes no Brasil é marcado principalmente por uma visão humanista e filosófica que delimitou as tendências tradicionalistas. Muito embora esses métodos sejam opostos em termos de esclarecer os papéis entre professor e aluno ainda hoje são evidentes suas influências nas ações escolares de arte e escolhas pedagógicas e estéticas de professores.

Até a primeira metade do século XX, o ensino da arte era voltado essencialmente para o ensino técnico, concentrado predominantemente na imagem do professor. De certa forma, competia a ele transmitir aos seus alunos os códigos ligados a padrões estéticos variados, mas que possuíam em comum o fato de que todos baseavam sua proposta na reprodução de modelos.

Entre os anos de 1920 e 1970, o advento da estética modernista possibilitou as escolas 
brasileiras uma nova experiência no âmbito do ensino das artes no Brasil. Nesse momento, o ensino das artes volta-se para o desenvolvimento natural da criança, colocando em primeiro plano suas necessidades e aspirações valorizando assim, suas formas de expressão e valorização do mundo. (PCN, 1997, pág. 23)

Pode-se dizer que esse fato tenha caracterizado um avanço, pois as aulas de artes passaram a assumir um caráter mais expressivo, buscando a espontaneidade e valorizando o crescimento ativo e progressivo do educando. As aulas de artes acabaram por se configurar em um espaço de criação, propiciando a livre auto-expressão dos alunos.

Apenas em 1971, a arte passou a ser incluída no currículo escolar pela Lei de Diretrizes e Bases da Educação Nacional com o nome de Educação Artística (PCN, 1997, pág. 24). Apesar disso, ela é considerada "atividade educativa" e não disciplina. Essa situação agravou-se durante os anos de 1970-1980, quando a arte passou a ser tratada como uma formação de caráter indefinido, mostrando assim que o sistema educacional estava apresentando dificuldades de base.

Somente com a Lei n. 9.394/96 o ensino de artes passou a ser obrigatório na educação básica: "O ensino da arte constituirá componente curricular obrigatório, nos diversos níveis da educação básica, de forma a promover o desenvolvimento cultural dos alunos" (Lei de Diretrizes e Bases da Educação Nacional art. 26, paràgrafo2)

\section{A Participação do Livro Didático no Ensino de Artes}

Muito embora grandes teóricos da Arte/Educação no Brasil venham tentando apontar caminhos que respondam a questão de qual é exatamente a função do ensino da arte nas escolas, isso ainda não está claro suficiente para alguns professores. Existe ainda um certo descompasso entre o trajeto de constantes perguntas e formulações que compõem a produção teórica de arte e o acesso dos professores a essa produção. Assim, sem uma consciência clara de sua função e sem um alicerce consistente da arte como uma área do conhecimento com seus conteúdos específicos, a ação pedagógica fica prejudicada na hora de formular um quadro de referências conceituais e metodológicas. Isso acaba por culminar na falta de um material didático de qualidade que dê suporte às aulas teóricas.

Nota-se que inicialmente, na primeira metade do século XX, o ensino das Artes Visuais era de caráter quase que totalmente prático, concentrando seu foco para a transmissão de padrões das culturas predominantes. Neste modelo tradicional, valorizava-se principalmente as habilidades manuais e os "dons artísticos" demonstrando assim uma visão predominantemente utilitarista e 
imediatista das Artes Visuais. Nesse ponto os manuais configurariam apoio suficiente, pois, naquele momento, o ensino da arte concentrava-se em modelos convencionais retirados e selecionados por eles deste tipo de material.

Contudo, com as diversas reviravoltas que o ensino de artes sofreu ao longo dos anos, alguns dos apoios metodológicos utilizados pelos professores acabaram por se mostrar ineficientes em alguns aspectos, como se verá adiante.

A problematização do material pedagógico utilizado pelos professores de Artes Visuais passa pela questão de como a prática de arte se relaciona com o ensino de história das Arte. Assim, o esboço do diagnóstico referente ao apoio didático que vem sendo utilizado nas aulas de Artes Visuais direciona o foco de sua pesquisa para turmas de $6^{\circ}$ e $7^{\circ}$ anos do Ensino Fundamental de Escolas Públicas da Secretaria de Educação do Distrito Federal. Essa escolha justifica-se pelo fato de que nessa fase o ensino de arte ainda se configura frequentemente de forma predominantemente prática. Neste caso, entende-se por prática de arte uma mera transmissão das técnicas de desenho ou pintura, por exemplo, sem contextualizá-las em um processo artístico histórico. Esse fato acaba por levantar suspeitas de que a ausência de uma transmissão ou mecanismo que faça com que as informações teóricas façam parte da metodologia aplicada, de alguma forma preocupa e cria a necessidade de algum tipo de recurso que auxilie o docente a promover uma integração da teoria e da prática. Nesse ponto específico surge a questão do apoio metodológico utilizado nas escolas. O que ocorre aqui não é o detrimento de um aspecto em virtude de outro, mas sim a possibilidade de um caminho que alie um ao outro para criar uma educação estética satisfatória. A prática educativa está embasada não no que se acostumou a denominar talento ou dom, mas na capacidade de experimentação de cada um.

A questão sobre a forma de ensino mais utilizada pelos arte/educadores é muito complexa e merece uma atenção especial. Segundo Beatriz Cabral, autora do artigo "A relação Bacharelado Licenciatura e a Natureza da Prática Pedagógica em Artes” há que se pensar numa reeducação do corpo docente como um todo em termos de teoria e prática (uma série de seminários regionais, a exemplo das mudanças curriculares em outros países, por exemplo).

Neste mesmo artigo, a autora responsabiliza o mau ensino na Educação Superior dos licenciados pelo fato da teoria e prática independente de qualquer privilégio, estar sendo mal ensinada. Isso porque o texto mostra que, de um modo geral, a Licenciatura tem se constituído na verdade pelo curso de Bacharelado acrescido das disciplinas pedagógicas sem se levar em consideração o fato de que o ensino de artes possui certas especificidades que muitas vezes não são atendidas por essa formação causando assim uma deficiência na formação dos professores de Artes Visuais.

A autora afirma ainda que disciplinas associadas à formação do professor como Psicologia e 
Sociologia da Educação da Arte, Fundamentos da Arte na Educação, entre outras ministradas nas primeiras fases, pouco acrescentaram à prática de ensino nas últimas fases, uma vez que o espaço de tempo entre elas inviabilizou qualquer aproximação ou experiência intercurricular.

Pode-se afirmar que as disciplinas de Artes Visuais, apesar de muitas vezes serem desprezadas por alguns alunos por a considerarem de caráter recreativo, possui um certo privilegio sobre as outras por possuir um caráter de fácil articulação com diversas áreas do conhecimento. Porém, articular Arte/Educação com outras disciplinas envolve capacitação dos educadores, das escolas e dos meios artísticos atuantes. Esses meios devem possuir conhecimentos suficientes acerca de variadas concepções de arte, usando-a como um ponto de ligação entre o saber e a prática cultural.

Apesar disso, neste projeto, é preferível não entrar nos méritos da formação do professorado no Brasil, evitando assim a incumbência do material didático de substituir uma suposta má formação de base dos professores, como propõe em algum momento Cristina d'Ávila em seu livro Decifra-me ou te devorarei - $O$ que pode o professor frente ao livro didático ? (2008). Com isso esclareço que o material didático será compreendido aqui apenas como um apoio pedagógico, não o responsabilizando assim por todo encaminhamento das ações pedagógicas na sala de aula. Essa tarefa normalmente é prerrogativa do professor.

De alguma forma, essa "fácil articulação" das Artes Visuais acaba por se refletir também na forma como esse conteúdo é administrado. No entanto, são muito comuns casos em que os professores de artes acabam por recorrer a apoios que vão além do livro didático recomendado pela escola, como reproduções de obras de arte e bibliografias próprias, isso, infelizmente, mais pela necessidade do que por qualquer outro motivo. Por mais que o fato dos professores estarem buscando recursos que vão além do que propõe os livros adotados pelas instituições de ensino pareça benéfico a primeira vista, essa atividade pode implicar numa "atomização" dos recursos. Isso quer dizer que esse constante exercício de "bolar atividades" (sic) propicia um afastamento do eixo pedagógico que, em última instância, é a proposta principal de um livro de apoio, afastando os discentes de uma linha constante de desenvolvimento. 


\section{CAPÍTULO II \\ "Não existe livro didático perfeito"}

“...esse está me servindo. Não existe livro didático perfeito, (...) não é aprofundado demais, ideal para séries iniciais.” (sic.)

Certamente o arte/educador é o principal responsável pelo desenvolvimento e aprendizagem dos educandos. Cabe a ele ajudar os alunos a melhorar sua sensibilidade crítica e seus conhecimentos teóricos e práticos. Para tal, exige-se do material didático que ele seja adequado ao currículo e que auxilie o professor na hora de possibilitar esta reflexão.

Dentre todos os recursos pedagógicos disponíveis aos docentes, o livro didático ocupa um lugar de destaque. Isso se comprova no fato de que os professores entrevistados durante a pesquisa referiram-se ao livro didático como o principal objeto de aprendizagem. Há casos ainda em que ele acaba por se configurar como o pilar fundamental das atividades coordenadas em sala de aula. Somente este fato já se coloca como motivo suficiente para uma investigação mais aprofundada. Contudo, acredito ser mais urgente nesse momento questionar se estes pilares são suficientemente consistentes. Este é o problema central que surgiu durante o desenvolvimento deste projeto. Sob este aspecto, entra em discussão uma série de questionamentos nos quais objetiva-se verificar se esses objetos de aprendizagem oferecem suporte necessário ao professor em sala de aula.

Essa aproximação à problematização do livro didático é de caráter qualitativo, pois utiliza variados procedimentos e instrumentos para coleta de informações. Além disso, recorre também à análise documental na qual foram verificados documentos como conteúdos programáticos e programas de curso. Entretanto, o principal meio utilizado foi uma entrevista estruturada em um questionário onde foram colhidos dados específicos sobre o tema abordado. Estes procedimentos visam apontar uma direção que nos demonstre a situação atual dos livros didáticos utilizados pelos profissionais da área de Artes Plásticas.

No livro A arte na Educação escolar, (REZENDE, 1997), são citados alguns procedimentos para o desenvolvimento das aulas de arte como, por exemplo, organizar atividades de ensino e aprendizagem que permitam o aprofundamento dos conteúdos escolares em arte por meio de elaborações práticas e teóricas. Entre esses procedimentos o autor chama atenção para o uso de materiais didáticos.

Infelizmente, no decorrer das entrevistas com os professores da rede pública de ensino, ficou claro que o material utilizado como apoio didático, quando existe, apresenta diversos problemas, o que obriga o professor a buscar outros meios que complementem seu material pedagógico próprio. Muito embora essa iniciativa do professor seja vista como benéfica em um primeiro momento, os motivos que os levam a recorrer a outros meios nem sempre são os melhores, nesse caso, a 
deficiência dos materiais didáticos à disposição. De qualquer forma, a ausência desse tipo de material dificulta ainda mais o trabalho dos professores, que tem que conviver diariamente com problemas dos mais variados tipos em sala de aula.

Nas duas escolas da Secretaria de Educação do Distrito Federal pesquisadas, percebeu-se constantemente, assim como nas conversas mantidas com profissionais da área de Artes Visuais e nas entrevistas uma clara insatisfação no tocante ao material didático adotado pelas instituições de ensino, o Projeto Radix. Atualmente, a Rede Pública de Ensino do Distrito Federal optou por adotálo como livro didático vigente que se trata na verdade de uma coleção de livros didáticos que além das Artes Visuais, abrange outras disciplinas, trazendo propostas pedagógicas para outros campos do conhecimento. A princípio, ele parece estar sofrendo uma rejeição por parte dos professores que o vêem como um suporte inconsistente, como pode-se perceber no transcorrer deste projeto. De acordo com Mariney Helena da Luz, professora temporária da Rede Pública de Ensino do Distrito Federal no Recanto das Emas, “o que acontece é que eles nos entregam o conteúdo a ser passado e nós temos que correr atrás.” (sic). Essa situação transparece também nas palavras de Érica Guedes, licenciada em Artes Visuais e docente no Centro de Ensino Fundamental 802 do Recanto das Emas: “Eu utilizo o projeto Radix com complementos, pois ele (o livro) é muito fraco”. (ver anexo B)

Ainda sobre o projeto "Radix", ambas professoras entrevistadas bem como todos os outros professores com quem manteve-se contato, reforçam que os referidos livros didáticos são muitas vezes confusos para o currículo escolar por não acompanhar o Projeto Político Pedagógico da escola ou ainda por ser superficial e pobre de imagens em alguns aspectos. Este quadro vem reforçar a situação inadequada em que se encontra o material didático nas Escolas de Ensino Público do Distrito Federal.

Outra questão importante levantada pela professora Érica Guedes, que também possui Graduação em Artes Cênicas é que existe uma deficiência nos livros didáticos no que diz respeito a uma proposta que englobe também as Artes Cênicas e a Música. Para ela, não deveria haver uma separação entre as modalidades da arte nos livros didáticos. Curiosamente, desde que a portaria 30 da Secretaria de Educação foi baixada, o ensino polivalente com relação às artes foi implantado. Assim, o professor deve dominar todas as áreas das artes, como a Música, as Artes Visuais e as Artes Cênicas. De qualquer modo, não cabe a esse texto tocar em um assunto que já foi e continua sendo alvo de tantas polêmicas, mas é realmente pertinente salientar aqui que apesar de existir essa cobrança por parte da rede pública com relação aos professores, os livros didáticos não acompanharam esse desenvolvimento. Ela nos coloca ainda que mesmo que os livros venham passando por diversas revisões desde o ano passado, seu conteúdo continua superficial, apresentando erros conceituais grosseiros, ainda não se adequando ao currículo.

Se, por um lado, os livros didáticos adotados pelo sistema público de ensino deixam a 
desejar, por outro, as de escolas particulares parecem não sofrer do mesmo problema. Em entrevista com Ana Paula Barbosa, professora de artes do Colégio Mackenzie, o livro didático A arte de se fazer arte, de Denize Haddad e Dulce Gonçalves Morbin (2004), adotado pela instituição de ensino, vem se apresentando como suporte suficiente: "esse está me servindo. Não existe livro didático perfeito, mas esse possui uma prática interessante e não é aprofundado demais, ideal para séries iniciais." (sic.). Além dela, Mariney, que também é professora na Colégio JK, em nenhum momento se manifesta contrária ao livro didático adotado na instituição de ensino na qual ela leciona.

Dessa forma, fica claro também uma defasagem dos apoios didáticos utilizados pelos professores da rede pública em relação aos professores da rede privada de ensino. Na maioria dos casos, a rede pública de ensino do Distrito Federal não utiliza nenhum material didático além do já citado projeto Radix. 


\section{Considerações Finais}

Mesmo que se proponha desde o início a ser apenas uma breve aproximação à problematização do livro didático voltado para o ensino de artes no Distrito Federal, esta pesquisa preliminar nos levam a refletir a respeito das propostas desenvolvidas no âmbito da produção de apoios pedagógicos que auxiliem o professor de artes plásticas a cumprir com o seu papel em sala de aula. Mais do que isso, é necessário questionar se os apoios didáticos adotados pelas instituições de ensino público no Distrito Federal vem oferecendo subsídios suficientes ao professor para que ele cumpra seu papel. Apesar de tantas reviravoltas ao longo do processo de reconhecimento das Artes Visuais como área de conhecimento, ainda se faz necessário movimentar o quadro atual e tornar o ensino da arte uma prática significativa para quem dela participa. É preciso maior empenho por parte dos profissionais da arte e das autoridades governamentais para que ela deixe de ser apenas um mero apêndice pedagógico de outras disciplinas, ou, como foi várias vezes relatado informalmente ao longo desta pesquisa, um meio utilizado para organização de festas.

O ensino de Artes Visuais se configura hoje como uma área do saber, uma disciplina com origem, história, questões próprias e metodologia. Assim como em outras áreas do conhecimento, não há uma homogeneidade entre as abordagens nesta área. Talvez apenas nos pressupostos mais abrangentes. Ao nos depararmos com a situação atual na qual se encontra o livro didático de Artes Visuais atualmente, percebemos que ele é apenas um sintoma de um problema muito maior que vem se apresentando durante anos no sistema público de ensino.

Outro ponto que cabe ressaltar, é que foi perceptível neste contexto, que existe uma defasagem muito grande das escolas da rede pública em relação às instituições particulares no tocante ao material didático utilizado. Enquanto os professores da rede particular possuem livros didáticos que se revelam um apoio didático consistente o suficiente para apoiar suas ações em sala de aula, os da rede pública de ensino, além de serem inconsistentes, demonstram um descompasso gritante em relação às políticas pedagógicas da instituição.

A ênfase dada ao trabalho do arte/educador não isenta o conjunto dos outros recursos da responsabilidade de promover uma educação estática em sua totalidade. Uma proposta pedagógica em arte, por melhor que seja, não se sustenta se não puder contar com recursos de qualidade.

Durante todo esse percurso, foi recorrente na fala dos professores e coordenadores, principalmente nas da rede pública de ensino, o fato de que um material didático satisfatório faz falta e que seria de grande importância possibilitando a igualdade de participação e construção do saber, desenvolvendo no aluno a compreensão do que se faz em arte no país e no mundo, de forma a estruturar cidadãos com uma formação estética, capaz de dialogar facilmente com os códigos artísticos, ficando demonstrado assim que o ensino da arte não se configura em um movimento 
unilateral onde o conhecimento parte do professor para o aluno, mas sim que o conhecimento seja construído passo a passo pelo aluno, enquanto cabe ao professor instruí-lo pelo caminho do conhecimento de uma educação estética de qualidade e completa.

Ao contrário da vivência como aluno em sala de aula, e como professor observador em Estágio Supervisionado 1, o processo de regência nos dois estágios subseqüentes caracterizou uma abertura para que se inferisse às problematizações levantadas ao longo desta monografia. Acredito que a pesquisa que se seguiu a essas preocupações surgidas durante o decorrer da minha vida acadêmica, que possuíam o objetivo de se colocar como estudo preliminar dos problemas decorridos da ausência de um apoio pedagógico de qualidade, conseguiu alcançar seus objetivos, mas necessita futuramente de um diagnóstico completo a respeito das questões levantadas. 


\section{Referências Bibliográficas}

ALVES-MAZZOTI, A. J. E GEWANDSZNAJDER, F. O Método nas Ciências Naturais e Sociais Pesquisa Quantitativa e Qualitativa. 2, ed. São Paulo: Pioneira Thomson, 2002.

BARBOSA, Ana Mae e Frange, Lucimar Bello P. Inquietações e Mudanças no Ensino da Arte.

CABRAL, Beatriz A.V. “A relação Bacharelado - Licenciatura e a Natureza da Prática Pedagógica em Artes", 2002

Disponível em: http://www.ceart.udesc.br/Revista_Arte_Online/VoHYPERLINK

"http://www.ceart.udesc.br/Revista_Arte_Online/Volumes/bacharelado-

licenciatura.htm"lumes/bacharelado-licenciatura.htm

Acesso em 26/06/2011

D' ÁVILA, Cristina Maria. Decifra-me ou te devorarei - O que pode o professor frente ao livro didático ?. Salvador: EDUNEB, 2008

PARÂMETROS CURRICULARES NACIONAIS ( $1^{\circ}$ a $4^{\circ}$ série): volume 6 , Arte. Secretaria de Educação, 1997

Disponível em: $\quad$ http://portal.mec.gov.br/seb/arquivos/pdf/livro06.pdfHYPERLINK "http://portal.mec.gov.br/seb/arquivos/pdf/livro06.pdfHYPERLINK

\%20\%22http://portal.mec.gov.br/seb/arquivos/pdf/livro06.pdf\%22"

Acesso em 21/06/2011

REZENDE, Maria F. e FERRAZ, Maria Heloísa C. De T.” A Arte na Educação Escolar”. São Paulo, Ed: Cortez, 1997.

Disponível em: http://www.caracolimaginario.com/paragrafo aberto/rml arteduca.htmlHYPERLINK "http://www.caracolimaginario.com/paragrafo_aberto/rml_arteduca.htmlHYPERLINK \%20\%22http://www.caracolimaginario.com/paragrafo\%22"

$\underline{\text { Acesso em 20/06/2011 }}$ 


\section{ANEXO A}

\section{ROTEIRO DE ENTREVISTA}

Nome: Mariney Helena da Luz Data: 29/06/11

Escola: JK - Valparaíso - Rede Pública- Mauá - Vila das Crianças

\section{1- Qual a sua formação?}

R- Graduada em Artes Plásticas com ênfase em Computação Gráfica.

\section{2- Conte sobre sua experiência em sala de aula.}

R- Atuo na área há cinco anos entre contrato temporário e estou 4 meses no JK.

Leciono de $5^{\circ}$ a $8^{\circ}$ série e também o ensino médio.

É um pouco complicado, porque os alunos vem da $4^{\circ}$ série com uma mentalidade de que arte é recreação. Fica um tanto complicado esse primeiro contato, mas depois eles acostumam.

\section{3- Usa materiais didáticos? Se sim, Qual? Se não, Porque?}

R-Sim data show e livros adotados pelas instituições- exceto a rede pública.

$\mathrm{Jk}$ - livro arte de fazer arte $5^{\circ}$ a $8^{\circ}$ série

Graça Proença- Ensino Médio

Projeto radix- Vila das crianças e rede pública

Rede pública - Aprendendo Arte.

\section{4- Gostaria de ter material didático? Porque?}

R- Sim, os livros didáticos são confusos para o currículo escolar. Muitas vezes não bate com a programação, ou seja com Projeto Político Pedagógico da escola.

\section{5- Você poderia citar algum ponto positivo e negativo dos materiais didáticos utilizados}

\section{atualmente}

R- Na maioria o conteúdo é superficial ou esclarece de mais e muitas vezes esse esclarecimento não condiz a série, são conteúdos que ainda serão vistos a frente. 
6- Na sua opinião, como seria o material didático ideal?

R- Aquele que seja adequado a série ministrada.

7- Como se dá na prática a relação qualitativa e quantitativa da teoria e da prática no ensino de artes nas $6^{\circ}$ séries $\left(7^{\circ}\right.$ anos) e $7^{\circ}$ série ( $8^{\circ}$ anos $)$ ?

R- A prática deve ser um complemento da teoria, e com ela esclarecer a que por ventura ficou falha. Isto serve claro somente para questões levantadas por meio de exercícios. No caso trabalho com cores. 


\section{ANEXO B \\ ROTEIRO DE ENTREVISTA}

Nome: Érica Guedes Data: 06/07/11

Escola: Centro de Ensino Fundamental 802 do Recanto das Emas

\section{1- Qual a sua formação?}

R- Artes plásticas na UNB.

2- Conte sobre sua experiência em sala de aula.

R- 2 anos Contrato Temporário

2 anos Escola Pública

3 anos Escola Particular

\section{3- Usa materiais didáticos? Se sim, Qual? Se não, Porque?}

R-Sim, Projeto Radix complemento, pois ele é muito fraco. Acaba pesquisando na Net para visar esse complemento. Agora consegui uma versão nova. Não é adequado ao currículo, é superficial, contém erros grosseiros, mas ainda é um dos melhores apesar disso, pobre de imagens.

\section{4- Gostaria de ter material didático? Porque?}

Sim. Inclusive um que seja polivalente entre as 3 artes.

5- Você poderia citar algum ponto positivo e negativo dos materiais didáticos utilizados atualmente.

R-ponto positivo mais barato

o negativo é o que eu já citei. 
6- Na sua opinião, como seria o material didático ideal?

R- Polivalente, aliado ao currículo.

7- Como se dá na prática a relação qualitativa e quantitativa da teoria e da prática no ensino de artes nas $6^{\circ}$ séries $\left(7^{\circ}\right.$ anos) e $7^{\circ}$ série ( $8^{\circ}$ anos $)$ ?

R- O maior problema que enfrento é livre- expressão dos meninos. Eles são muitos presos, muitas vezes não acompanham proposta. 


\section{ANEXO C \\ ROTEIRO DE ENTREVISTA}

Nome: Ana Paula Barbosa

Data: 06/07/11

Escola: Mackenzie

\section{1- Qual a sua formação?}

R- Formada em artes cênicas- UNB

Formada em artes visuais- Faculdade Dulcina.

\section{2- Conte sobre sua experiência em sala de aula.}

R- Experiência de anos não de lembra bem, para ensino médio e atualmente assumiu $1^{\circ}$ turma de $6^{\circ}$ ano de Ensino Fundamental.

\section{3- Usa materiais didáticos? Se sim, Qual? Se não, Porque?}

R-Sim. Para ensino fundamental estou usando- A arte de fazer arte de Denise Haddad e Dulce Gonçalves Morbin. Editora Saraíva. È o livro adotado pela instituição.

\section{4- Gostaria de ter material didático? Porque? \\ R- Estou satisfeita com o que estou usando atualmente.}

\section{5- Você poderia citar algum ponto positivo e negativo dos materiais didáticos utilizados atualmente?}

R- Inicialmente eu considerava esse livro fraco. No entanto ele foi revisado a partir do ano passado, tornando-se mais dinâmico e didático, melhorou consideravelmente. Resolveu alguns erros conceituais que apresentava antes. Possui breves históricos dos artistas que estão sendo estudados, o que é muito bom. Tem uma parte interessante de história da arte do Brasil diferente da Graça Proença que apresenta diversos erros conceituais.

Por ser bom, corre o risco de engessar a aula. Se ficar se apegando ao livro didático constantemente. 


\section{6- Na sua opinião, como seria o material didático ideal?}

R- Esse está me servindo. Não existe livro didático perfeito. Mas esse possui uma prática interessante e não é aprofundado de mais, ideal para as séries iniciais.

7- Como se dá na prática a relação qualitativa e quantitativa da teoria e da prática no ensino de artes nas $6^{\circ}$ séries $\left(7^{\circ}\right.$ anos $)$ e $7^{\circ}$ série $\left(8^{\circ}\right.$ anos $)$ ?

R- Nas questões práticas, a maioria das vezes segue as propostas do livro. Existem outras demandas do próprios colégio o que força a procurar outras propostas. Mas ainda assim ele tenta contextualizar as propostas do livro em sala de aula. 